\title{
A Multiple Intelligences Model for Design: Developing the Ways Designers Think as Design Disciplines Expand
}

\author{
DENNIS M. CHEATHAM ${ }^{1}$
}

1. Miami University, Oxford, OH, USA

SUGGESTED CITATION: Cheatham, D. "A Multiple Intelligences Model for Design: Developing the Ways Designers Think as Design

Disciplines Expand.” Dialectic, 1.2 (2017): pgs. 75-100. DOI: http://dx.doi.org/10.3998/dialectic.14932326.0001.205

\section{Abstract}

Design has traditionally sought to produce the best outcome(s) possible-artifacts, systems, services, experiences, or interactions - without exploring other opportunities and consequences. Design research and practice are increasingly expanding beyond a decidedly formal focus, manifesting as emerging design disciplines, transdisciplinary practices, and mindsets that bring co-creation, experience, and systemic approaches to design processes. Traditional design education models that focus primarily on form-giving are too ideologically narrow or practically inflexible to address this type of expansion. As designers seek to develop innovative solutions to increasingly complex matters by synthesizing concepts from disciplines not traditionally associated with design, a new framework is needed to facilitate a more inclusive and expansive type of design learning.

This essay explores the current state of traditional (i.e., artifact-centric, production-minded) design education, and makes a case to adapt it to an array of recent changes in the areas of design research and practice. A spectrum of design mindsets is defined and explored to clarify different ways designers frame their thinking to consider usability, co-creation, experience, and systemic relationships when researching and developing in emerging design areas such as transition design, service design, and experience design. An overview of Multiple Intelligence theories is provided to support a proposed framework for design education called the PACES Multiple Intelligences Model for Design (PACES = Practical, Analytical, Creative, Emotional, and Social). PACES components are described in detail, and examples of how these can be effectively applied to support the needs of contemporary design educators and students are shared. This essay concludes with a report of what has been learned after a yearlong implementation of PACES in an American, university-level communication design program. 



\section{A Multiple Intelligences Model for Design: Developing the Ways Designers Think as Design Disciplines Expand}

DENNIS M. CHEATHAM

\section{Introduction}

Over the last thirty-plus years, concepts like usability, accessibility, and the critical examination and assessment of experiences and systems have become essential aspects of design processes and design research approaches and methods. The design thinking movement has expanded design's impact, and it has become clear that design processes are capable of being applied within and across an increasingly wide variety of situations, from business innovation to addressing "complex sociotechnical systems". " Risk-averse clients have come to expect the designers they hire to formulate and operate evidence-based research methods like A/B comparison testing and focus groups to support design decision-making and to prove the efficacy of design outcomes. As design research and practice expand into new arenas, different and sometimes new ways of facilitating design learning are needed.

I will discuss a spectrum of mindsets that designers, their clients, and their collaborators are now embracing as the range of matters design research, education, and practice are addressing expand to consider detailed experiences as well as sweeping social innovations. With regard to each of these mindsets, I will identify ways that research methods, theory, and design practices are

1

Norman, D. and Stappers, P. "DesignX: Complex Sociotechnical Systems," She Ji: The Journal of Design, Economics, and Innovation, 1.2 (2015): pgs. 83-106. becoming more diverse to more effectively address tangible and intangible aspects within these matters so relevant design interventions may be developed and implemented. In conclusion, I will propose a model for design education that can be used to facilitate and assess learning as design mindsets and research needs expand. 


\section{Learning Design}

2

Davis, M. "Raising the Bar for Higher Education." In The Education of a Graphic Designer, edited by S. Heller, p. 16. New York, NY, USA: Allworth Press, 2005.

3

Sanders E., Stappers P. Convivial Toolbox: Generative Research for the Front End of Design. Amsterdam, The Netherlands: BIS Publishers, 2013: p. 258.

\section{4.}

Irwin, T. "Transition Design: A Proposal for a New Area of Design Practice, Study, and Research." Design and Culture, 7.2 (2015): pgs. 229-246.

5

Norman, D. "Why Design Education Must Change." Core77 (blog). 26 November 2010. Available at http:// www. core77. com/posts/17993/whydesign-education-must-change-17993 (Accessed 2 0ctober 2011).

\section{6}

Poggenpohl, S., Winkler, D. "In Closing... What Have We Learned From Failure?." Visible Language, $44.1(2010)$ : p. 130.

\section{7}

Archer, B. "Design as a Discipline." Design Studies, 1 (1979): p. 19.

\section{8}

Cross, N. “Design Research: A Disciplined Conversation." Design Issues, 15.2 (1999): p. 7.

\section{9}

Cross, N. Designerly Ways of Knowing. London, UK: Springer, 2006.
Design education in traditional design disciplines like architecture, visual communication design, and interaction design has tended to value knowledge, thinking, and skills that focus on helping design students develop formal design abilities and understandings. Many North American (and European, Australasian and South American) design programs still champion aesthetic and functional prowess as the greatest indicators of design excellence among student populations. When these aspects of design are overemphasized, not enough attention is given to teaching students about how design functions in broader contexts, why it is culturally relevant, and how and why it now has the widespread economic, political, environmental and technological impacts that it does. ${ }^{2}$ However, in emerging design disciplines like designing for service, experience, social impact, and transition, the purposes design outcomes are intended to achieve are given primacy over the formal design outcome. ${ }^{3-4}$

The work of integrating traditional and emerging design disciplines poses a challenge for design education programs who value form as the ultimate indicator of design success. Emerging design disciplines expand the need for those who plan and teach their curricula to integrate theory, research, and the development of empirical skill and understanding. As this occurs, emerging designers learn to embrace the study of human behavior in complex societies, psychology, and other concepts from the social sciences as significant aspects of the design process. ${ }^{5-6}$ Design knowledge, thinking, and skills are now being applied to address complex, multifaceted, systems-based problems that require a synthesis of understanding of traditional and emerging design practices. Preparing emerging designers to effectively plan, operate, and sustain career paths that exist in this new reality has stretched many of the established conventions of what it means to teach and practice design. It tests and, in some places, expands design's disciplinary boundaries, and in turn raises a question about how it should be taught: as a type of artistic endeavor, an extension of science, or as something that exists somewhere between?

Across much of the scholarly literature pertinent to it, design is often cited as being neither wholly art nor science, but argued instead as a "third area," distinct from science and the humanities. ${ }^{7-8}$ Designers have been found to think differently and to act in a specific manner that suggests that "ways of knowing" " in design are distinct and unique in comparison with those that have evolved within other disciplines. Donald Schön's The Reflective Practitioner: How Professionals Think in Action ${ }^{10}$ and Nigel Cross's Designerly Ways of 
Knowing ${ }^{11}$ provide the most well-known scholarship in this area. Cross even proposed the concept of a unique design intelligence that enables designers to address and define ambiguous problems. ${ }^{12}$ As design expands its influence and attention beyond form alone, design education must also expand the scope and content of what designers need to learn - augmenting abilities to create form with attention to fostering development of the ways designers think. This expansion can be illustrated, and thus better understood, by examining different design mindsets that span traditional and emerging design disciplines.

\section{Design Mindsets}

Whether they are consciously held or not, mindsets shape priorities and decision making. For instance, a mindset can determine the scope of a design project (from micro to macro to meta), the type of research approach needed to most effectively understand its implications and impacts (for design, into design, through design), ${ }^{13}$ or what aspect of a given phenomenon is of concern (sacred, symbolic, science). ${ }^{14}$ As designers become more involved in emerging design disciplines that endeavor to positively alter experiences, functions within communities and systems, and guide social transformation, it behooves designers to cultivate an awareness of the role and application of a full spectrum of mindsets. Traditional design disciplines tend to espouse and nurture the development of mindsets that focus on form. However, adopting a broader spectrum of mindsets to augment those that emphasize the creation of form can help designers gain different, and more widely informed, perspectives

Schön, D. The Reflective Practitioner: How Professionals Think in Action. New York, NY, USA: Basic Books, 1983.

11

Cross, N, Designerly Ways of Knowing. London, UK: Springer, 2006.

12

Ibid., p. 127

13

Frayling, C. "Research in Art and Design." Royal College of Art Research Papers, 1.1 (1993): pgs. 1-5.

\section{4}

Hendry, P. "Narrative as Inquiry." The Journal of Educational Research, $103(2010)$ : pgs. $72-80$. when researching and creating. With the ability to hold a broader set of mindsets, designers can identify a dynamic range of aspects entailed in an issue being addressed, clarifying relevant theory and methods to apply in design research and practice.

An overview of design mindsets, their qualities and areas of focus is depicted in table 1.

\section{The Form Mindset}

The form mindset is most concerned with the empirical details and functionalities yielded by the outcome(s) of the design process. Design competitions where formal outcomes are lauded and win awards, or design critiques wherein the discussion is chiefly about the appearance of the "thing" that do not address at least some aspects of the social, cultural, historical or political context it inhabits are examples of this mindset. Research that occurs in the 


\begin{tabular}{|c|c|c|c|c|c|}
\hline MINDSET & FORM & USABILITY & CO-CREATION & EXPERIENCE & SYSTEMIC \\
\hline NON-DESIGNER AS & audience & user & designer & participant & stakeholder \\
\hline DESIGNER AS & expert & evaluator & translator & facilitator & collaborator \\
\hline KEY QUESTION & $\begin{array}{l}\text { How can we design } \\
\text { the visual and textual } \\
\text { form so the intended } \\
\text { message is received? }\end{array}$ & $\begin{array}{l}\text { How can this design be } \\
\text { formatted so people } \\
\text { can access its features? }\end{array}$ & $\begin{array}{l}\text { In what ways should } \\
\text { design be created so } \\
\text { it is authentic and } \\
\text { relevant to the needs of } \\
\text { those live with it daily? }\end{array}$ & $\begin{array}{l}\text { How can this be } \\
\text { designed so it is an } \\
\text { engaging, meaningful, } \\
\text { and memorable } \\
\text { experience? }\end{array}$ & $\begin{array}{l}\text { How can design } \\
\text { interventions positively } \\
\text { impact complex } \\
\text { challenges, both real } \\
\text { and perceived? }\end{array}$ \\
\hline KEY CONCERN & communication & access & unarticulated needs & sensemaking & interrelationships \\
\hline TIME FRAME & $\begin{array}{l}\text { the moment of } \\
\text { engagement with the } \\
\text { design }\end{array}$ & $\begin{array}{l}\text { length of engagement } \\
\text { with the design }\end{array}$ & during designing & $\begin{array}{l}\text { during and after } \\
\text { engagement with the } \\
\text { design }\end{array}$ & $\begin{array}{l}\text { long before and after } \\
\text { design is implemented }\end{array}$ \\
\hline DESIGN CONCERNS & $\begin{array}{l}\text { color theory, line } \\
\text { quality, font selection, } \\
\text { brand message, } \\
\text { hierarchy, image } \\
\text { selection, concept, } \\
\text { copywriting, pacing, } \\
\text { composition, materials }\end{array}$ & $\begin{array}{l}\text { translation, text- } \\
\text { to-speech, button } \\
\text { size, type size, visual } \\
\text { contrast, characters } \\
\text { per line, drop downs, } \\
\text { menus, web browser, } \\
\text { smartphone, packaging, } \\
\text { physiology }\end{array}$ & $\begin{array}{l}\text { relevance, problem } \\
\text { solving, solution format, } \\
\text { media, language, } \\
\text { documentation, } \\
\text { collaboration, creation, } \\
\text { discovery, defining } \\
\text { needs, co-creator } \\
\text { comfort }\end{array}$ & $\begin{array}{l}\text { worldview, culture, } \\
\text { emotion, affordance, } \\
\text { motivation, different } \\
\text { abilities, sound, ambient } \\
\text { temperature, senses, } \\
\text { texture, timbre, } \\
\text { sequence }\end{array}$ & $\begin{array}{l}\text { worldview, culture, } \\
\text { communities, systems, } \\
\text { logistics, reciprocity, } \\
\text { sustainability, } \\
\text { organizational } \\
\text { structures, policies, } \\
\text { perception, trust }\end{array}$ \\
\hline RESEARCH & $\begin{array}{l}\text { web searches, site } \\
\text { visits, press visit, paper } \\
\text { or materials review }\end{array}$ & $\begin{array}{l}\text { analytics, eye tracking, } \\
\text { A/B testing, surveys, } \\
\text { observations, focus } \\
\text { groups, interviews }\end{array}$ & $\begin{array}{l}\text { observations, focus } \\
\text { groups, charrettes, } \\
\text { camera study, LEGO } \\
\text { modeling, affinity } \\
\text { diagrams }\end{array}$ & $\begin{array}{l}\text { observations, focus } \\
\text { groups, interviews, } \\
\text { participant observation, } \\
\text { charrettes, video } \\
\text { ethnography }\end{array}$ & $\begin{array}{l}\text { focus groups, } \\
\text { interviews, longitudinal } \\
\text { studies, charrettes, } \\
\text { community forums, } \\
\text { affinity diagrams }\end{array}$ \\
\hline PROCESSES & $\begin{array}{l}\text { sketching, full-size } \\
\text { comps, style guides, } \\
\text { press check, prototypes }\end{array}$ & $\begin{array}{l}\text { wire framing, } \\
\text { prototypes, card } \\
\text { sorting, personas }\end{array}$ & $\begin{array}{l}\text { create toolkits, } \\
\text { acting, play, mind- } \\
\text { mapping, transcription, } \\
\text { prototypes }\end{array}$ & $\begin{array}{l}\text { experience mapping, } \\
\text { audio interface } \\
\text { plans, storyboarding, } \\
\text { prototypes, materials } \\
\text { study }\end{array}$ & $\begin{array}{l}\text { GIGA-mapping, } \\
\text { prototypes, causal } \\
\text { loop diagrams, low } \\
\text { resolution prototyping }\end{array}$ \\
\hline THEORY & $\begin{array}{l}\text { art, literary, cultural, } \\
\text { rhetorical }\end{array}$ & $\begin{array}{l}\text { semiotics, cognition, } \\
\text { universal design }\end{array}$ & $\begin{array}{l}\text { creativity theories, } \\
\text { generative design }\end{array}$ & $\begin{array}{l}\text { Social Cognitive Theory, } \\
\text { Theory of Planned } \\
\text { Behavior }\end{array}$ & $\begin{array}{l}\text { Soft Systems } \\
\text { Methodology, } \\
\text { systems theories }\end{array}$ \\
\hline
\end{tabular}

TABLE 1: An overview of design mindsets that illustrates design knowledge, thinking, and skills, as well as participant roles inherent in each. By depicting mindsets this way, it is possible to compare their various aspects and methods, how they relate to one another specifically and generally, and ways each mindset can be applied in re-search and practice. 
15

Krug, S. Don't Make Me Think!:

A Common Sense Approach to Web Usability, 2nd ed. Berkeley, CA, USA: New Riders Publishing, 2006.

16

Sanders, E. Maketools. Available at: http://www.maketools.com/ (Accessed 18 November 2015).

17

Sanders E., Stappers P. Convivial Toolbox: Generative Research for the Front End of Design. Amsterdam, The Netherlands: BIS Publishers, 2013. form mindset may include selecting typefaces that make a given typographic configuration "feel” like a 1950's malt shop, or tilting a smartphone horizontally to determine how to configure the formal elements that constitute a menu for a mobile app. Historically in design education, teaching students to marry well-realized formal compositions that visually communicate an essential "concept" have been the primary (and sometimes only) concerns addressed in graphic, or visual communication design classrooms.

\section{The Usability Mindset}

The emphasis of the usability mindset is to reduce the "friction" between a given user or audience member and the user interface he/she is being challenged to use so that access, or the ability to use, is perceived to be effortless for as many of these people as possible. Often, the ideal in the usability mindset is for design processes to yield outcomes that feel so intuitive to users that minimal thinking about the workings of their parts is required. ${ }^{15}$ When usability is the primary mindset being operated by the designer or researcher, the scenario of use drives a majority of the inquiry and creation process (a "scenario of use" refers to a situation, and the various conditions and factors that affect its evolution, within which a given designed product or experience is to be used by a specific user). Usability is often thought of in an interaction design context as a means to guide the creation of the user interfaces that functionalize websites and smartphone apps. It should be borne in mind that many of these interfaces operate independently of media. For instance, research for usability can include testing typographic legibility of a concert program in low-light conditions, or observing the paths children take when walking down a steep hill to a playground to determine the most preferred places to integrate walkways.

\section{The Co-Creation Mindset}

This mindset is valued by designers who invite non-designer participants to be involved in design and development projects as design experts. The designer's role while operating a co-creation mindset is to facilitate a discovery or development process that reveals unarticulated needs among specific groups of users or audiences. This interaction is supported by the use of tools and methods to guide design decision-making like toys, acting, drawing, and stickers that depict simple components that are often referred to as "generative toolkits." 16-17 Research that involves the operation of a co-creative mindset can lead to working sessions wherein townhouse renters work with designers to construct ideal 
18

Jensen ]. "Designing for Profound Experiences." Design Issues, 30.3

(2014): pgs. 39-52.

\section{9}

Wang, c. "Service Design for UX Designers." Usability Counts (blog)

13 May 2013. Available at: http:// www. usabilitycounts. com/2013/05/13/ service-design-for-ux-designers/ (Accessed 11 January 2017). 20

Ryan, A. "A Framework for Systemic Design." FORMakademisk, 7.4 (2014): pgs. 1-14.

21 Davis, M. “Toto, I've Got a Feeling We're Not in Kansas Anymore..." Paper presented at AIGA Massaging Media 2 Conference, Boston, Boston, MA, USA, April 2008.

22

Jones, J. Design Methods, Kindle Edition. New York, NY, USA: Wiley, 2008. Kindle Locations 1503-1504. doggie doors for their situations involving use by particular dogs, or charrettes wherein working single parents develop a mail delivery service that encourages socializing with neighbors while also creating necessary playtime for kids.

\section{The Experience Mindset}

When operating an experience mindset, researchers address psychosocial, cultural, relational, behavioral, cognitive, and physical uniqueness to develop and study how these factors affect the experiences of groups and individuals as they engage in particular types of activities. ${ }^{18}$ When designing for experiences, designers are not limited to working within a specific media. Instead, a transdisciplinary approach is often taken where input from non-design disciplines, as well as different types of design practices such as service, interaction, communication, sound and interior design, are integrated to research and produce outcomes at a multi-sensory level. ${ }^{19}$ Experience design outcomes are not always visual or tangible, and have resulted in the configuration of audio interfaces for Apple's Siri and Amazon's Alexa intelligent personal assistant programs. With this mindset, the examination of sense-making and the memorability of the nuanced qualities of feelings and resulting actions facilitated by design interventions are of primary importance. Research involving experience design can include studying the psychological impacts of virtual reality-enhanced activities on feelings of loneliness among expatriates, or trying to determine the most ideal procedures to enhance the experiences of non-native language speakers when they are challenged to register for driver's licenses in various types of governmentally controlled settings.

\section{The Systemic Mindset}

When operating a systemic mindset, designers integrate systems thinking and design thinking to inspect and analyze situations as a whole and as networks of interrelated components where matters of concern include formal design outcomes, natural phenomena, the viewpoints and behavior of different groups of people, as well as changing social and economic conditions. ${ }^{20}$ A systemic mindset holds that aspects of that which has been designed are valued in their relation to how they affect the functions of other nodes in a system. ${ }^{21}$ Approaching design research with a systemic mindset broadens the scope of what researchers can investigate across the levels of what J. Christopher Jones refers to as "components, products, systems, and communities." 22 An example of research that has been guided by the systemic mindset is a study of the 
23

Trubek, L. G., \& Das, M. “Achieving Equality: Healthcare Governance in Transition." American Journal of Law and Medicine, 29 (2003): pgs. 395-421.

24

Bennett, A. "The Rise of Research in Graphic Design." in Design Studies: Theory and Research in Graphic Design, edited by A. Bennett, pgs. 14-23. New York, NY, USA: Princeton Architectural Press, 2006. 25 Rittel, H. W. J., Webber, M. "Dilemmas in a General Theory of Planning." Policy Sciences, 4 (1973): p. 166. perception of healthcare equality in communities where transportation, advertising, government healthcare benefits, and other real and perceived factors are accounted for. ${ }^{23}$

\section{Advocating for A More Holistic Approach to Designer Development}

Designing with different mindsets at levels that account for the intimate experiences of given groups of people, as well as their involvement in massive social transitions, presents designers with numerous opportunities for innovation. In each of these scenarios, designers are active participants in the problem-solving process, from definition to the implementation and testing of design interventions. Thanks to the design thinking movement, designers' knowledge, thinking, and skills have earned them a position as integral members of problem-solving teams. However, when designers are confronted with "wicked problems" (or aspects of them), they must be able to engage in types of thinking, draw from bases of knowledge, and operate skills that exceed the typical scope of traditional, formal design. Wicked problems, like the facilitation of widespread, effectively facilitated healthcare and the broad sustenance of human rights in given societies, require design researchers and practitioners to effectively identify, frame, and define the contextual parameters that surround problems. These processes entail the management and operation of much more broadly informed and deeply plumbed approaches and methods than mere "problem-solving." For example, designers who engage in usability testing must develop research processes and associated instruments, gather, analyze and interpret qualitative and quantitative data, and finally identify frameworks and themes to help them use the data they have gathered to determine what is relevant and what is not. To inform this type of decision-making, both tangible and intangible factors that balance or disrupt reason and emotion all matter, including practical matters of economics and technology access, as well as socioculturally imposed belief and value systems.

Intuition in and of itself is no longer a sufficient driver for design, ${ }^{24}$ and the case could be made that it never really was, as its inherent intentionality is one of the primary aspects of design that separates it from art. Reasoning and research skills have become necessary to inform and guide design processes as designers work on interdisciplinary teams to address issues that transcend the limitations of the form mindset. Embedded within Rittel and Webber's oft-referenced description of the properties of a wicked problem lies a warning: "The planner has no right to be wrong." 25 The consequences of 
26

Janzer, C. \& Weinstein, L., "The

Citizen Designer: A Cautionary Note," in Developing Citizen Designers, edited by E. Resnick, pgs. 287-

289. New York, NY, USA: Bloomsbury Academic, 2016

\section{7}

Gibson, M. R. “Learning to Design Backwards: Examining a means to introduce human-centered design processes to teachers and students." Design and Technology Education: An International Journal, 21.1 (2016): pgs. $8-20$.

\section{8}

Leslie Owen Wilson's work at her website, "The Second Principle" helped guide much of this inquiry into multiple intelligences. Wilson,

L. The Second Principle. Available

at: http://thesecondprinciple.com/ (Accessed 9 June 2016). missteps, sweeping generalizations, and maligned methods can and do wreak significant damage to project stakeholders, or "users and audiences," when co-creation, experience, and systemic mindsets are employed and projects operate at social levels. ${ }^{26}$ Engaging in narrowly informed design thinking and cursory attempts at engaging in ethnography in an attempt to "solve" these types of problems is inadequate because they do not account for enough of the variables that occur in wicked problem situations where design outcomes are integrated as interventions to affect positive change. Depending on the specific situation, variables that must be accounted for include actor/participant belief and value systems, existing economic and social conditions, and malleable, invisible variables like the perception of a given public policy agenda. ${ }^{27}$

A more holistic approach to designer development is warranted if learners in design programs are to sustain careers as researchers and practitioners that consider the importance of accounting for physical and mental human uniqueness as a means to guide their design decision-making. In the increasingly diversifying realms of design education, meeting this challenge has transcended and will continue to transcend the need for skills training. A core-level approach to educating emerging designers is required that emphasizes examining the different ways designers think, as opposed to merely emphasizing what they $d o$. To this end, the discipline of psychology provides us with diverse concepts of intelligence, or intellectual functioning, that are sufficiently holistic to guide how design education can be structured and facilitated to enable future designers to effectively utilize a more broadly and deeply developed range of design mindsets. This pluralistic approach allows for a conceptualization of intelligence as something that is more flexible and elastic than it is rigid and staid. It allows for the examination and incorporation of multiple intelligences to be accounted for in the purview of design education.

\section{Multiple Intelligences ${ }^{28}$}

Definitions of intelligence and how it is measured have been debated across a wide range of disciplines for over two millennia. Most familiarly, intelligence is quantified as an Intelligence Quotient (IQ) number. This value is used to quantify a person's intelligence related to their age and is based on how well individuals perform on standardized, problem-solving tests. However, the broad concept of intelligence advocated by the American Psychological Association (APA) in their Glossary of Psychological Terms debunks the validity of 
29

Gerrig, R., Zimbardo, P. Psychology and Life, 16th Edition. Boston, MA, USA: Allyn and Bacon. 2002.

\section{0}

Merriam-webster.com. "Intelligence." Available at: https://www.merriam-webster.com/dictionary/intelligence (Accessed 8 December 2016).

\section{1}

Gardner, H. Frames of Mind: The Theory of Multiple Intelligences. New York, NY, USA: Basic Books, 1983. 32

Gardner, H. Intelligence Reframed: Multiple Intelligences for the 21st Century. New York, NY, USA: Basic Books, 1999.

\section{3}

Davis, K. et. al. "The Theory of Multiple Intelligences," in The Cambridge Handbook of Intelligence, edited by R. Sternberg, S. Kaufman, pgs. 485-620. New York, NY, USA: Cambridge University Press, 2011.

"Howard Gardner: "We do not have a single intelligence." Teaching (blog). 19 September 2013. Available at http://blog.tiching.com/howard-gardner-inteligencias-multiples/ (Accessed 11 December 2016).

\section{5}

Fogarty, R., Stoehr, J. Integrating Curricula with Multiple Intel-

ligences: Teams, Themes, \& Threads, 2nd edition. Thousand Oaks, CA: Corwin Press, 2008.

\section{6}

Gardner, H. "The Theory of Multiple Intelligences: As Psychology, as Education, as Social Science." Howard Gardner (blog). 22 0ctober 2011. Available at: https:// howardgardner01. files.wordpress. com/2012/06/473-madrid-oct-22-2011. pdf (Accessed 11 December 2016). intelligence as being signified by a single IQ number. The APA supports that intelligence is:

the global capacity to profit from experience and to go beyond given information about the environment. ${ }^{29}$

Merriam-Webster defines intelligence as:

the ability to learn or understand or to deal with new or trying situations ${ }^{30}$

Both definitions indicate that intelligence is about adapting to and going beyond the limitations imposed by a given set of circumstances within a given situation — neither suggests intelligence should be indicated or signified by a single, fixed number. Harvard psychologist Howard Gardner, who in 1983 proposed the Theory of Multiple Intelligences, is a widely-respected developmental psychology researcher who began advocating for the concept of multiple intelligences instead of a single IQ intelligence in $1983 .{ }^{31-32}$ Along with Gardner, psychologists Robert Sternberg, Daniel Goleman, and John D. Mayer and Peter Salovey have independently conducted research providing evidence that intelligence should not thought of as being a singular, finitely measurable concept. ${ }^{33}$ Gardner's definition of intelligence(s) seemingly aligns with a core set of design characteristics:

“...the biological and psychological potential to analyze information in specific ways, in order to solve problems or to create products that are valued in a culture."

If the expanding spectrum of design mindsets requires an expansion of the range of knowledge, thinking, and skills designers must be able to operate effectively, and intelligences are now thought of as being malleable and expansive, it stands to reason that Multiple Intelligence theories could be valuable for shaping design education as it also expands. Applying and operationalizing multiple intelligences to enhance teaching and learning is not a new idea. Since their inception, Multiple Intelligence theories have been used to shape curriculum and learning outcomes around the world. ${ }^{35-37}$ In order to integrate 
PRACTICAL GROUP

practical Sternberg ${ }^{3637}$ work within constraints; adapt to environments meet deadlines; allow enough time to complete a project; follow given criteria/guidelines; attempt achievable projects
We never had to rush the design process because ample time was planned for each project stage."

ANALYTICAL GROUP

\begin{aligned} \hline analytical $\quad$ Sternberg $^{3637} &$ apply logic and reason when \\ & evaluating, assessing and \\ & addressing problems; \\ & critical thinking \end{aligned}

design outcomes supported by evidence and clear justification; employ a methodical, iterative process to imporve work; make logical conclusions to inform design decisions
"A smartphone app was appropriate because research revealed apps were apartment dwellers' preferred means of communication.

\begin{tabular}{lllll}
\hline $\begin{array}{l}\text { logical- } \\
\text { mathematical }\end{array}$ & Gardner ${ }^{29}$ & $\begin{array}{l}\text { identify relationships between } \\
\text { phenomena; recognize causal } \\
\text { and correlational relationships; } \\
\text { complete accurate calculations }\end{array}$ & $\begin{array}{l}\text { recognize and evaluate system behaviors that } \\
\text { suggest need for design; front-end web coding; } \\
\text { design rigorous research }\end{array}$ & $\begin{array}{l}\text { "Our research revealed that bicycle usage } \\
\text { increased 83\% when wayfinding signage } \\
\text { was installed, suggesting trail signs may } \\
\text { be a smart investment for the city." }\end{array}$ \\
\hline naturalistic & Gardner ${ }^{29}$ & $\begin{array}{l}\text { categorize natural phenomena, } \\
\text { environments, organisms, and } \\
\text { features due to high degree of } \\
\text { sensory perception }\end{array}$ & $\begin{array}{l}\text { attention to detail when observing human } \\
\text { behavior and environment enhances product } \\
\text { testing/research; ability to sort guides complex } \\
\text { information design decisions }\end{array}$ & $\begin{array}{l}\text { "By categorizing information using a } \\
\text { system of highly detailed characteristics, } \\
\text { the data visualization revealed } \\
\text { relationships between buying habits and } \\
\text { local weather patterns." }\end{array}$ \\
& & &
\end{tabular}

CREATIVE GROUP

\begin{tabular}{|c|c|c|c|c|}
\hline creative & Sternberg 3637 & $\begin{array}{l}\text { create new, novel, and } \\
\text { inventive concepts, ideas, } \\
\text { processes, and outcomes }\end{array}$ & $\begin{array}{l}\text { create innovative and unexpected design } \\
\text { outcomes and approaches; combine media/ } \\
\text { content in unique ways; research under- } \\
\text { addressed concepts }\end{array}$ & $\begin{array}{l}\text { "Designing the merry-go-round to pump } \\
\text { irrigation water was innovative. Area } \\
\text { kids needed a playground and their play } \\
\text { helped pump water to adjacent crops." }\end{array}$ \\
\hline linguistic & Gardner ${ }^{29}$ & $\begin{array}{l}\text { create with, assess, and } \\
\text { articulate words with attention } \\
\text { to meaning; considers tone, } \\
\text { inflection, and rhythm }\end{array}$ & $\begin{array}{l}\text { select appropriate words to communicate } \\
\text { nuance; improve usability by selecting tone for } \\
\text { different contexts and abilities }\end{array}$ & $\begin{array}{l}\text { "Instead of calling them 'employees' } \\
\text { let's call them 'team members' to } \\
\text { encourage a sense of comraderie } \\
\text { between workers." }\end{array}$ \\
\hline spatial & Gardner $^{29}$ & $\begin{array}{l}\text { plan, assess, perceive, and } \\
\text { develop arrangements of forms } \\
\text { and images, including real and } \\
\text { perceived spaces }\end{array}$ & $\begin{array}{l}\text { create packaging, industrial design, and } \\
\text { architecture; assess space needs for operating } \\
\text { services; mapping and visualization }\end{array}$ & $\begin{array}{l}\text { "Our festival map design clearly depicts } \\
\text { food vendor location in relation to the } \\
\text { main stage and the ATM machine." }\end{array}$ \\
\hline musical & Gardner $^{29}$ & $\begin{array}{l}\text { create, assess, and direct music } \\
\text { with sensitivity to rhythm, } \\
\text { timbre, tone, } \\
\text { and meter }\end{array}$ & $\begin{array}{l}\text { select an appropriate error sound for a } \\
\text { smartphone app or music that supports } \\
\text { meditation in a sacred space }\end{array}$ & $\begin{array}{l}\text { "That music is too playful and child-like for } \\
\text { the restaurant mood we're shooting for. } \\
\text { Can we find something more serene?" }\end{array}$ \\
\hline $\begin{array}{l}\text { bodily- } \\
\text { kinesthetic }\end{array}$ & Gardner $^{29}$ & $\begin{array}{l}\text { physically move and control } \\
\text { one's body to create or solve } \\
\text { problems }\end{array}$ & $\begin{array}{l}\text { use a stylus or operate a mouse; construct a } \\
\text { detailed model; use hand and body motions to } \\
\text { demonstrate how something is operated }\end{array}$ & $\begin{array}{l}\text { "Imagine my fist is the ball we're trying to } \\
\text { catch in the basket. I'm going to mimic } \\
\text { ways it may bounce if our design fails..." }\end{array}$ \\
\hline \multicolumn{5}{|c|}{ EMOTIONAL GROUP } \\
\hline emotional & $\begin{array}{l}\text { Mayer and } \\
\text { Salovey }{ }^{38} \\
\text { Mayer et al. }{ }_{41}^{39} \\
\text { Goleman }^{40}{ }^{31}\end{array}$ & $\begin{array}{l}\text { accurately articulate, express, } \\
\text { and interpret emotions in self } \\
\text { and in others }\end{array}$ & $\begin{array}{l}\text { develop conceptual design that effectively } \\
\text { communicates intended emotional content; } \\
\text { communicate complex, nuanced emotions }\end{array}$ & $\begin{array}{l}\text { "The 'Brain on Drugs' campign captured } \\
\text { the right kind of fear. We all know eggs } \\
\text { fry, but imagine if your brain. Scary stuff!" }\end{array}$ \\
\hline intrapersonal & Gardner $^{29}$ & $\begin{array}{l}\text { recognize and interpret one's } \\
\text { own moods, feelings, goals, } \\
\text { temperments, and intentions }\end{array}$ & $\begin{array}{l}\text { evaluate and guide career goals and preferences; } \\
\text { govern emotions in professional and personal } \\
\text { scenarios }\end{array}$ & $\begin{array}{l}\text { " "Designing fashion isn't as exciting as I } \\
\text { thought it would be. Researching global } \\
\text { fashion trends seems to be my real } \\
\text { interest." }\end{array}$ \\
\hline
\end{tabular}

SOCIAL GROUP

\begin{tabular}{|c|c|c|c|c|}
\hline social & $\begin{array}{l}\text { Mayer and } \\
\text { Salovey }{ }^{38} \\
\text { Mayer et al. }{ }^{39} \\
\text { Goleman }{ }^{4041}\end{array}$ & $\begin{array}{l}\text { effectively work with others } \\
\text { individually and in teams }\end{array}$ & $\begin{array}{l}\text { facilitate concensus with various stakeholders; } \\
\text { promote effective collaborative processes; } \\
\text { empower communities and/or individuals to } \\
\text { participate in design process }\end{array}$ & $\begin{array}{l}\text { "Thanks for meeting with me about } \\
\text { improving access to workplace health. } \\
\text { Tell me about your idea to install a gym in } \\
\text { our office-what would that look like? }\end{array}$ \\
\hline interpersonal & Gardner $^{29}$ & $\begin{array}{l}\text { recognize and interpret } \\
\text { others' moods, feelings, goals, } \\
\text { temperments, and intentions }\end{array}$ & $\begin{array}{l}\text { co-worker/collaborator relationships- } \\
\text { important for those in leadership roles }\end{array}$ & $\begin{array}{l}\text { "We all need a day away from the project. } \\
\text { On Friday we'll do a half-day at the park } \\
\text { for fun and lunch. Bring a comfy lawn } \\
\text { chair." }\end{array}$ \\
\hline
\end{tabular}

TABLE 2: A comparison of Multiple Intelligence theories. This table illustrates how intelligences are grouped into five areas and can be applied in different design scenarios. ${ }^{38-43}$ 
37

"Howard Gardner: "We do not have

a single intelligence." Teaching (blog). 19 September 2013. Available

at http://blog.tiching.com/howard-gardner-inteligencias-multiples/

(Accessed 11 December 2016).

\section{8}

Sternberg, R. The Triarchic Mind: A New Theory of Intelligence. New York: Viking Press, 1988.

\section{9}

Sternberg, R. Successful Intelligence: How Practical and Creative

Intelligence Determine Success in Life. New York, NY, USA: Penguin/Putnam, 1997.

\section{0}

Mayer, J. Salovey, P. "What is Emotional Intelligence?." In Emotional Development and Emotional Intelligence: Implications for Educators, edited by P. Salovey and D. Sluyter, pgs. 3-31. New York, NY, USA: Basic Books, 1997.

41

Mayer, J. Salovey, P. Caruso D. "Emotional Intelligence: Theory, Findings, and Implications." Psychological Inquiry 15.3 (2004): pgs. 197-215.

42

Goleman, D. Emotional Intelligence: Why it Can Matter More Than IQ. New York, NY, USA: Bantam Books, 2005.

Goleman, D. Social Intelligence: The New Science of Human Relationships. New York, NY, USA: Bantam, 2007.

\section{4}

Wilson, L. "Sternberg's Views on Intelligence." The Second Principle (blog) Available at: http://thesecondprinciple.com/optimal-learning/ sternbergs-views-intelligence/ (Accessed 2 January 2017).
Multiple Intelligences into a multiplicity of design learning scenarios, the creation of a useful framework specific to design education is warranted.

\section{The PACES Multiple Intelligences Model for Design}

Research into Multiple Intelligences has identified a broad range of intelligences with some overlaps between theories. I conducted a literature review in early 2017 to inform the development of a framework that could be used to apply these theories to design learning situations. After analyzing the most prominent Multiple Intelligence theories to determine and compare their common characteristics, five main groupings coalesced from thirteen named intelligences. These groupings include "Practical," "Analytical," “Creative," "Emotional," and "Social" intelligence groupings, hence the acronym "PACES". This process informed the creation of the PACES Multiple Intelligences Model for Design, which is depicted in table 2 and discussed below.

\section{Practical Intelligence: “Common Sense" or "Street Smarts" 44}

Practical intelligence manifests itself as the ability to meet deadlines and adapt to workplace culture and the conditions therein. Given that design is a very deadline-driven endeavor in both practice and research, these are important abilities to develop and hone. Professional design studios, consultancies and research labs are imbued with their own distinct cultures, and the ability to become a productive member of a design team working in these environments is highly valuable. The ability to utilize knowledge that has been cultivated by doing and learning from doing is necessary to formulate and engage in design research. This type of "common sense" is essential to framing, planning and operating a specific research program, and to selecting methods to use for data gathering, analysis and interpretation (which then guide decision-making). In each of these cases, possessing practical intelligence usually means that a designer will be more likely to succeed when working within logistical constraints imposed by factors like cost, scheduling, technological limitations and social norms.

\section{Analytical Intelligence: Critical Thinking and Reasoning}

The ability to think critically is important in design and research when developing, producing and assessing design outcomes. Critical thinking includes the ability to work iteratively, to repeatedly assess each revision of a design to determine if it is meeting goals, and then make appropriate revisions. Daniel 
45

Willigham, D. "Critical Thinking:

Why Is It So Hard to Teach?" Arts

Education Policy Review, 109.4

(2008): pgs. 21-29.
Willingham's definition of critical thinking is applicable here: “[It] consists of seeing both sides of an issue, being open to new evidence that disconfirms your ideas, reasoning dispassionately, demanding that claims be backed by evidence, deducing and inferring conclusions from available facts, solving problems...” 45 The ability to reason becomes especially valuable when designers formulate and conduct research because doing this requires them to objectively analyze data and make conclusions that inform design decision-making that is supported by this data.

\section{Creative Intelligence: Synthesis and Invention}

Design research is a generative process that requires identifying and defining a social, technological, economic or public policy matter to be addressed, sometimes following with an intervention that positively affects change on behalf of a group or individual. The ability to discover hidden connections between the factors or conditions that affect a given situation, and then synthesize new outcomes that stem from these connections is a source for innovation that creative intelligence makes possible. (These new outcomes can manifest themselves as artifacts, systems of artifacts, or new ways of doing, making or learning.) Designers are typically well-practiced at engaging in creative processes, so creative intelligence could be regarded as one of the intelligences that is "native" to design.

\section{Emotional Intelligence:}

Analyzing, Interpreting and Expressing Emotions

Emotions affect design processes across the full range of design mindsets. The ability to accurately interpret emotional nuances assists prosocial behavior in the workplace and the development of conceptual communication. Design researchers must accurately identify emotional factors when recording findings and defining effective design interventions. In practice and research, designed artifacts, systems, communities and processes are created to facilitate the evocation of intended emotional reactions, which requires the operation of at least a reasonably high level of emotional intelligence.

\section{Social Intelligence: Collaboration and Engagement with Others}

Design researchers and practitioners are routinely involved in a wide range of social interactions. From conducting interviews with stakeholders to presenting them with design outcomes, the ability to effectively and meaningfully

\section{8}


engage with other people-particularly those who may not share common viewpoints or possess the same stores of knowledge - is an intelligence that is highly valuable for design. As the broad array of cultural, technological, economic and public policy issues design will address in the coming years become more socially and societally complex, design teams will often be challenged to formulate and operate research which requires well-planned and facilitated collaboration and social engagement. Any meaningful, sustainable interaction with others requires social intelligence.

\section{“Applied” Intelligences}

Gardner's Multiple Intelligence Theory consists of eight intelligences, and six of these are not directly accounted for in the PACES Multiple Intelligences Model for Design. This is not because these intelligences are subordinate to the others, but, because in the context of design, they are best categorized as “applied" intelligences. Linguistic, spatial, and musical intelligences are often applied when creating and presenting formal design outcomes. The control of one's own movement involved in bodily-kinesthetic intelligence manifests itself in design when sketching, cutting and attaching material, or building models. Logical-mathematical intelligence is activated when measuring materials or coding. Naturalistic intelligence enables people to effectively categorize items, which affects grouping-intensive practices like those that occur during the processes that yield effective information design artifacts and systems. Table 2 depicts how these "applied" intelligences integrate into the PACES framework.

\section{Design Education and PACES}

The PACES Multiple Intelligences Model for Design was developed to provide a flexible framework for guiding and assessing learning in the undergraduate and graduate design programs at Miami University in Miami, Ohio, USA. These programs, facilitated within the Department of Art, include - as of this writing in the summer of 2017-a Communication Design Minor, a BFA (Bachelor of Fine Arts) in Communication Design, and an MFA (Master of Fine Arts) in Experience Design. In late spring and summer 2016, design faculty at Miami explored how the curricula that constituted their respective programs could best facilitate the development of a wide range of design mindsets among their students. In Fall 2016, the PACES Multiple Intelligences Model for Design was implemented as a distinct set of program-wide student learning outcomes at 
both the undergraduate and graduate levels. These learning outcomes are articulated as follows:

Practical Intelligence: Learners will be able to apply design processes and produce outcomes within practical constraints.

Analytical Intelligence: Learners will be able to demonstrate relevant and accurate decision making for needs being addressed.

Creative Intelligence: Learners will be able to generate inventive and engaging outcomes.

Emotional Intelligence: Learners will be able to accurately interpret and express emotions that are appropriate for the context.

Social Intelligence: Learners will be able to demonstrate an ability to effectively engage and collaborate with others.

Each of these learning outcomes are assessed at various junctures over the course of a learners' progress through the three design programs currently taught at Miami University. A rubric is used to facilitate these assessment activities, and it features the following categorical metrics: exemplary, mastery, developing, beginning, and weak. PACEs learning outcomes are intended to be formative, so no grade points are awarded for performance in PACES areas. Not all intelligences are assessed for every activity: for example, some activities may not have a strong social component because they require more individualized work from students. Course instructors determine which intelligences will be assessed depending on the features inherent in the assigned activity. In addition to PACES, assigned activities still include "traditional" learning outcomes that assess performance on seminal skills like typographic hierarchy or the development of theoretical frameworks to guide research. Learner performance for each of these outcomes constitute the graded portion of assignments and determine the course or project points that are earned per student.

PACES learning outcomes serve several key functions in the Miami University design programs. At a long-term, developmental and programmatic level, PACES is used to gauge how learners grow from the time they enter the program through graduation. At a short-term, course-based level, cumulative 
growth over a semester is assessed based on instructor evaluations of PACES learning outcome performance per specific assignments. At a planning level, PACES has informed how faculty plan course activities and projects, and this framework has also been used to guide a curriculum revision to all three degree programs that will be implemented in fall 2017.

\section{PACES at the Developmental Level}

Learners in the BFA in Communication Design are introduced to PACES as pre-Communication Design majors in the Pre-Communication Design course during their first year of undergraduate study. In this course, each intelligence area is discussed and explored through reading, writing, and engagement in a design project over a period of a three to six weeks. Learners who are admitted into the undergraduate Communication Design major via a faculty-facilitated portfolio review receive milestone feedback on their PACES development at two other times during their enrollments: from their employer once they have completed a required design internship, and after their culminating Degree Project Capstone experience at the culmination of their final semester of enrollment in the program. These three milestone evaluations will enable learners to compare their PACES growth over the course of four or more years. Learners in the MFA in Experience Design program follow a similar trajectory, with an initial assessment of PACES strengths and milestone feedback at two other times during their progress toward completing this degree. In each of these cases, feedback is provided electronically using the rubric supported by written or video comments delivered via Canvas Learning Management System, an online "classroom" where assignments, grading, discussions boards, and other course materials are hosted.

\section{PACES at the Course Level}

PACES supplements undergraduate and graduate curricula at the course level. In design courses, a mix of projects, assignments, and exercises are assigned to develop learners' knowledge, thinking, and skills in areas specific to Communication or Experience Design. As in many programs devoted to teaching these disciplines, design and research processes entail successive rounds of critique, discussion, and refinement. Performance on learning outcomes are assessed using a rubric, points are earned based on the determination of a level of performance, and informal feedback is provided by the instructor as given projects progress and at their conclusion. PACES intelligences are evaluated for 


\section{Design Miami OH Program-wide Learning Outcomes}

People are intelligent in many different ways. Our program defines these Multiple Intelligences for Design as a model we call PACES. Please evaluate the presentation using the five measures below.

Practical Intelligence: At what level did the presenters apply design processes and produce outcomes within practical constraints?

Examples: on-time, followed criteria or guidelines, included essential content to ensure clarity.

\begin{tabular}{|l|l|l|l|l|}
\hline Exemplary & Mastery & Developing & Beginning & Weak \\
\hline
\end{tabular}

Analytical Intelligence: At what level did the presenters demonstrate relevant and accurate decision making for needs being addressed?

Examples: well-reasoned, justified designs, met stakeholder needs, used iteration to improve work, made logical conclusions.

\begin{tabular}{|l|l|l|l|l|}
\hline Exemplary & Mastery & Developing & Beginning & Weak \\
\hline
\end{tabular}

Creative Intelligence: At what level did the presenters generate inventive and engaging outcomes?

Examples: unexpected approach and/or design outcome, integrated unique content combinations, examined under-addressed concepts, implemented new media.

\begin{tabular}{|l|l|l|l|l|}
\hline Exemplary & Mastery & Developing & Beginning & Weak \\
\hline
\end{tabular}

Emotional Intelligence: At what level did the presenters accurately interpret and express emotions that are appropriate for the context?

Examples: design that captured the right emotions for the communication, explored complex emotional content.

\begin{tabular}{|c|c|c|c|c|}
\hline Exemplary & Mastery & Developing & Beginning & Weak \\
\hline
\end{tabular}

Social Intelligence: At what level did the presenters demonstrate an ability to effectively engage and collaborate with others?

Examples: included a range of participants, methods that involved people and collaboration, empowered participants to have a voice in the work, considered communities and/or individuals as integral to the project.

\begin{tabular}{|l|l|l|l|l|}
\hline Exemplary & Mastery & Developing & Beginning & Weak \\
\hline
\end{tabular}

What was the presentation's greatest strength?

What is an area where the presentation could improve?

Anything else you'd like to share?

What is your overall impression of this presentation?

\begin{tabular}{|c|c|c|c|c|}
\hline 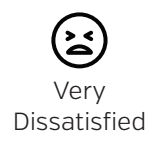 & $\bigodot_{\text {Dissatisfied }}$ & $\underbrace{}_{\begin{array}{c}\text { Neither Dissatisfied } \\
\text { Nor Satisfied }\end{array}}$ & $\underbrace{(\bullet)}_{\text {Satisfied }}$ & $\bigoplus_{\substack{\text { Very } \\
\text { Satisfied }}}^{0}$ \\
\hline
\end{tabular}

FIGURE 1: An evaluation sheet for assessing PACES learning outcomes. This form is completed by evaluators on a mobile device, computer, or on paper. These PACES learning out-comes are joined by specific assignment learning outcomes (not shown here) that are used for project grading. 
each activity to provide learners with feedback regarding how they performed on a single activity, so-depending on the course - learners may receive three to ten different PACES evaluations. This feedback is tailored to address the specific requirements of an assigned activity. The intent of offering this level of feedback is to provide formative and summative insights into ways learners develop as they progress through a course of study.

\section{PACES at the Planning Level}

PACES has shaped how curriculum is planned and developed across our programs. Its framework provides structure that allows faculty to evaluate planned activities and effectively coordinate how students plan and operate different intelligences over the course of a 15-week semester. Not all intelligences are activated in each assignment, but the model encourages faculty to consider ways that different intelligences could be activated and developed. By integrating learning objectives that involve knowledge construction and acquisition, thinking, and skills with intelligence-level objectives, class activities maximize broadly informed, deeply probative learning by activating these approaches simultaneously. With planning, different mindsets can be explored within the scope of a given project or course offering, design skills can be developed, and the development of multiple intelligences can be fostered. For example:

An undergraduate-level design project titled "People-Driven Design" challenges learners to define, develop, and design an outcome that would meet the unique "needs" or "desires" of an assigned persona based on that persona's traits. The assignment calls for random slips of paper to be given to each learner. These slips define persona traits for whom individual learners must create a "relevant outcome" to address a "need" or "want" within the constraints of the assigned persona context (practical). Research is then conducted to allow learners to understand more about the time and place where this persona lives or lived (if the year they received was in the past). Emotional, cultural, developmental, and other factors are researched that could help reveal the persona's unarticulated needs (emotional). Learners define a "need", or "set of needs" (creative), and support it/their existence with evidence (analytical). An iterative process of design development is operated (analytical). The project is presented to others in the class at the midway point of the semester, and peer reviews take place intermittently (social). After a final outcome is completed (creative), all resources are handed to another student to use for phase two of the project 

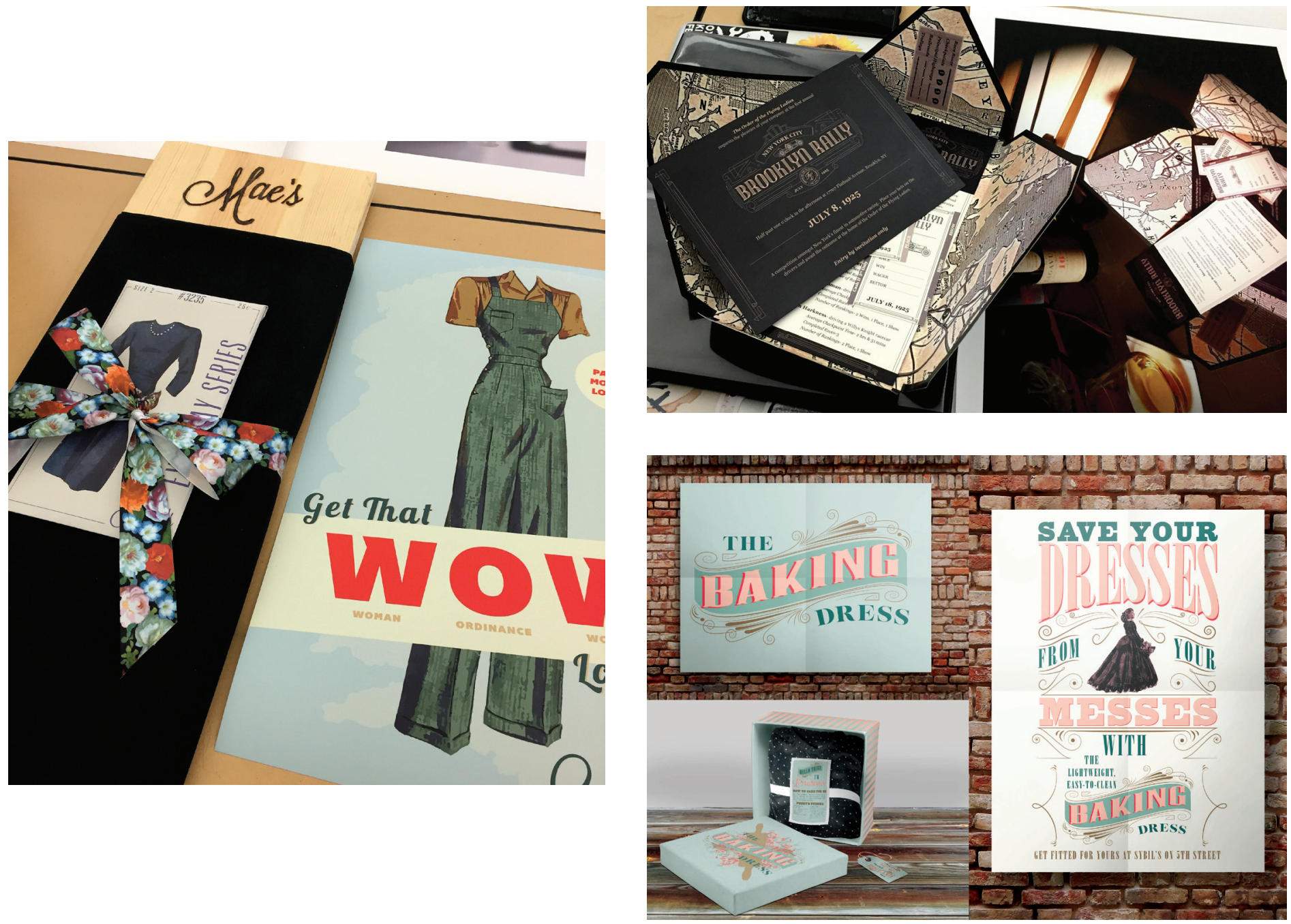

[CLOCKWISE]

FIGURE 2: Mae's fashion patterns and bundled fabrics were developed so clothing could be made within United States World War II rationing standards while activating the persona's love of sewing. Designed by Brittany Hogan.

FIGURE 3: A suite of materials for attending and betting on the Brooklyn Rally, a secret, upscale auto race in 1925 that would appeal to rally racing aficionados seeking excitement during the era of prohibition. Designed by Kendra Huspaska.

FIGURE 4: The Baking Dress, designed to align with fashion standards in 1860's America but still allow women to enjoy baking as a hobby and not damage their everyday wear. Designed by Tina Zenzola. 
(emotional, social). All of this must be completed before the project deadline, per assigned specifications (practical).

In response to the "People-Driven Design" project requirements, one learner produced wild west outlaw trading cards based on a persona of an 8-year-old boy who loved baseball and lived in DuBois, Wyoming in 1870. Another learner produced a brand of poker-themed cologne packaging for a persona who was a 21-year-old contemporary man living in Las Vegas who enjoys perfumes. This project is an example of how a Communication Design-centric activity can be planned so room is left for learners to apply different mindsets, activate multiple intelligences, and still produce portfolio-level work. Examples of this work are depicted in figures 2-4. Similar projects in courses including Design Research Methods, A History of Design, and Letterpress for Designers are being developed using PACES to inform their formats and learning activities.

\section{PACES So Far, and Looking Ahead...}

As with almost any design intervention, intended and unintended consequences cannot be fully anticipated until whatever has been designed is made and then implemented or distributed, and the PACES Multiple Intelligences Model for Design is no different. After using the model for one academic year, much has been learned about its effects on the students' learning experiences, the faculty, and the evolution of the design curricula at Miami University. For example, during several Pre-Communication Design (first-year undergraduate) class meetings and during the undergraduate entry portfolio review, several learners casually referred to some of the multiple intelligence areas in discussion. When PACES was informally discussed with several design professionals in the Cincinnati area (which is geographically near Miami University), these designers shared that the model could be a helpful metric to clarify graduates' strengths in their résumé materials. These instances suggest that PACES may have the potential to grow into a valuable, shared vocabulary for faculty, students, and potential employers.

One learner in an advanced-level course responded negatively to their practical intelligence being scored as "developing" because his assignment was turned in late. The learner cited that he did not care to have his intelligence assessed. The instructor invited a discussion about the matter which was resolved by clarifying the reason for the score. While this situation was resolved amicably, it should be noted that the concept of intelligence-particularly how it is perceived and signified - is one that should not be taken lightly, as it can 
4.6

Dweck, C. Self-Theories: Their Role in Motivation, Personality and Development. Philadelphia, PA, USA: Psychology Press, 2000.

\section{7}

Värlander, S. "The Role of Students' Emotions in Formal Feedback Situations." Teaching in Higher Education 13.2 (2008): pgs. 145-56.

48

Cramp, A. Lamond, C. Coleyshaw, L. Beck, S. “Empowering or Disabling? Emotional Reactions to Assessment Amongst Part-Time Adult Students." Teaching in Higher Education 17.5 (2012): pgs. 509-521. 49

Fogarty, R., Stoehr, J. Integrating Curricula With Multiple Intelligences: Teams, Themes, \& Threads. 2nd edition. Thousand Oaks, CA, USA: Corwin Press, 2008. be used as a measure of an individual's position in society. To be perceived as "deficient" in intelligence could be interpreted to mean that an individual has reduced agency, which can lead to feelings of powerlessness. ${ }^{46-48}$ This highlights the need for programs to clearly communicate that PACES is a formative framework that was developed in the interest of fostering broadly informed, deeply reflective student growth. So far, this has been communicated to students directly by instructors as they talk about the intents and purposes of these holistic evaluations. To reduce potential power discrepancies, we are exploring how PACES could be used to allow students to evaluate faculty performance as they endeavor to facilitate learning. In each of these cases, developing and fostering a supportive culture of growth is important, so intelligence evaluation and feedback is exchanged in its intended spirit.

Since the model's implementation, the range of different learning activities in courses has expanded significantly. By starting with the identification and qualification of intelligences as drivers for human development, the types of learning activities being developed have been less likely to follow suit with existing project parameters and assignments. There has been a significant increase in the number of collaborative design projects at all levels of the program. Activities where learners are expected to write as part of the design process have been implemented, which has resulted in an increase in the development of critical thinking skills. As PACES becomes more routine in our program, we will continue to assess how broadly and deeply it is adopted among our student populations, as well as the ways in which it manifests itself.

The primary hope for the PACES Multiple Intelligences Model for Design is that it will make documenting the process of design learner growth clearer, both for those who must assess it, and for the learners themselves. Ultimately, this documentation can reveal how learners' initial strengths can evolve into areas where they have the greatest potential to develop further. As design research and practice expand, activating a range of mindsets across traditional and emerging design disciplines is becoming harder in the short amount of time learners are enrolled in design education programs. Unifying these experiences is efficient and effective, and more effectively models modern practice where design activities are fluid and not segmented into every-other-day class meetings, course numbers, and semesters. ${ }^{49}$ By integrating mindsets, intelligences, and skills learning in design education processes, the complexity of emerging practices can be simultaneously explored. 
These are exciting times for design and designers. Instead of designers' perceived value to society as being people who mostly engage in working processes that yield aesthetically compelling forms, designers are now applying their knowledge, thinking, and skills in ways that establish them as key participants in advancing communities and individuals. Design researchers are applying research approaches and methods in inter- and trans-disciplinary teams to reveal insightful knowledge and promising solutions for challenging issues. The future success of design in these areas will rely on practitioners and researchers developing an array of intelligences to equip them for the work ahead.

\section{References}

Archer, Bruce. “Design as a Discipline.” Design Studies 1 (1979): 17-20.

Bennett, Audrey. “The Rise of Research in Graphic Design,” In Design Studies:

Theory and Research in Graphic Design, edited by Audrey Bennett, 14-23.

New York, NY, USA: Princeton Architectural Press, 2006.

Cramp, A., C. Lamond, L. Coleyshaw, and S. Beck. "Empowering or Disabling? Emotional Reactions to Assessment Amongst Part-Time Adult Students.” Teaching in Higher Education 17.5 (2012): 509-21.

Cross, Nigel. “Design Research: A Disciplined Conversation.” Design Issues 15.2 (1999): 105-10.

Cross, Nigel. Designerly Ways of Knowing. London, UK: Springer, 2006.

Davis, Katie, Joanna Christodoulnu, Scott Seider, and Howard Gardner. "The Theory of Multiple Intelligences," In The Cambridge Handbook of Intelligence, edited by Robert J Sternberg, and Scott Barry Kaufman, 485620. New York, NY, USA: Cambridge University Press, 2011.

Davis, Meredith. "Raising the Bar for Higher Education," In The Education of a Graphic Designer, edited by Steven Heller, 13-18. New York, NY, USA: All-worth Press, 2005.

Davis, Meredith. “Toto, I've Got a Feeling We're Not in Kansas Anymore...” Presentation at AIGA Massaging Media 2 Conference in Boston, Boston, MA, USA, April 4, 2008.

Dweck, Carol. Self-Theories: Their Role in Motivation, Personality and Development. Philadelphia, PA, USA: Psychology Press, 2000. 
Fogarty, Robin, and Judy Stoehr. Integrating Curricula With Multiple Intelligences:

Teams, Themes, \& Threads. Thousand Oaks, CA, USA: Corwin Press, 2008.

Frayling, Christopher. "Research in Art and Design.” Royal College of Art Research Papers 1.1 (1993): 1-5.

Gardner, Howard. Frames of Mind: The Theory of Multiple Intelligences. New York, NY, USA: Basic Books, 1983.

Gardner, Howard. Intelligence Reframed: Multiple Intelligences for the 21st Century. New York, NY, USA: Basic Books, 1999.

Gardner, Howard. “The Theory of Multiple Intelligences: As Psychology, as Education, as Social Science." Presentation on the occasion of his receipt of an honorary degree from José Cela University and the Prince of Asturias Prize for Social Science, Madrid, Spain, October 22, 2011.

Gerrig, Richard J., and Zimbardo, Philip G. Psychology and Life. Boston, MA, USA: Allyn and Bacon, 2002. http:/www.apa.org/research/action/glossary.aspx.

Gibson, Michael R. "Learning to Design Backwards: Examining a Means to Introduce Human-Centered Design Processes to Teachers and Students." Design and Technology Education: An International Journal 21.1 (2016): 8-20.

Goleman, Daniel. Emotional Intelligence: Why it Can Matter More Than IQ. New York, NY, USA: Bantam Books, 2005.

Goleman, Daniel. Social Intelligence: The New Science of Human Relationships. New York, NY, USA: Bantam, 2007.

Hendry, Petra Munro. "Narrative as Inquiry.” The Journal of Educational Research 103 (2010): 72-80.

"Howard Gardner: "We Do Not Have a Single Intelligence.” blog.tiching. com, last modified September 9, 2013, http://blog.tiching.com/ howard-gardner-inteligencias-multiples/.

Irwin, Terry. "Transition Design: A Proposal for a New Area of Design Practice, Study, and Research." Design and Culture 7, no. 2 (2015): 229-46.

Janzer, Cinnamon L., and Lauren S. Weinstein. “The Citizen Designer: A Cautionary Note," In Developing Citizen Designers, edited by Elizabeth Resnick, 287-89. New York, NY, USA: Bloomsbury Academic, 2016.

Jensen, Jesper L. “Designing for Profound Experiences.” Design Issues 30.3 (2014):39-52.

Jones, J. Christopher. Design Methods. Translated by 4 August 2015. New York, NY, USA: Wiley, 2008. 
Krug, Steve. Don't Make Me Think!: A Common Sense Approach to Web Usability. Berkeley, CA, USA: New Riders, 2006.

Mayer, John D., and Peter Salovey. “What is Emotional Intelligence?,” In Emotional Development and Emotional Intelligence: Implications for Educators, edited by P. Salovey, and D. Sluyter, 3-31. New York, NY, USA: Basic Books, 1997.

Mayer, John D., Peter Salovey, and David R. Caruso. "Emotional Intelligence: Theory, Findings, and Implications.” Psychological Inquiry 15.3 (2004): 197-215.

Merriam-webster.com. “Intelligence.” last modified December 8, 2016, https:// www.merriam-webster.com/dictionary/intelligence.

Norman, Donald. "Why Design Education Must Change.” last modified October 2, 2011. http://www.core77.com/posts/17993/why-designeducation-must-change-17993.

Norman, Donald A., and Pieter Jan Stappers. "DesignX: Complex Sociotechnical Systems." She Ji: The Journal of Design, Economics, and Innovation 1.2 (2015): 83-106.

Poggenpohl, Sharon Helmer, and Dietmar Winkler. "In Closing... What Have We Learned From Failure?” Visible Language 44.1 (2010): 127-139.

Rittel, H. W. J., and Melvin M. Webber. "Dilemmas in a General Theory of Planning.” Policy Sciences 4 (1973): 155-69.

Ryan, Alex J. “A Framework for Systemic Design.” FORMakademisk 7, no. 4 (2014): 1-14.

Sanders, Elizabeth B.N., and Pieter Jan Stappers. Convivial Toolbox: Generative Research for the Front End of Design. Amsterdam, The Nethlerands: BIS Publishers, 2013.

Sanders, Liz. "Maketools.” last modified November 18, 2015. http://www.maketools.com/.

Schön, Donald A. The Reflective Practitioner: How Professionals Think in Action. New York, NY, USA: Basic Books, 1983.

Sternberg, Robert J. The Triarchic Mind: A New Theory of Intelligence. New York, NY, USA: Viking Press, 1988.

Sternberg, Robert J. Successful Intelligence: How Practical and Creative Intelligence Determine Success in Life. New York, NY, USA: Penguin/Putnam, 1997.

Trubek, L. G., \& Das, M. “Achieving Equality: Healthcare Governance in Transition." American Journal of Law and Medicine, 29 (2003): pgs. 395-421. 
Värlander, Sara. “The Role of Students' Emotions in Formal Feedback Situations." Teaching in Higher Education 13.2 (2008): 145-56.

Wang, Cathy. "Service Design for UX Designers.” last modified January 11, 2017, http://www.usabilitycounts.com/2013/05/13/service-design-for-uxdesigners/.

Willingham, Daniel T. “Critical Thinking: Why is it So Hard to Teach?” Arts Education Policy Review 109.4 (2008): 21-29.

Wilson, Leslie Owen. “The Second Principle.” last modified June 9, 2016, http:// thesecondprinciple.com/.

Wilson, Leslie Owen. “Sternberg's Views on Intelligence.” last modified January 2, 2017, http://thesecondprinciple.com/optimal-learning/ sternbergs-views-intelligence/.

\section{Biography}

Dennis Cheatham is a design researcher, designer and educator with over fourteen years of professional design experience as a graphic designer, interaction designer, copywriter and creative director. He is currently an Assistant Professor of Communication Design at Miami University in Oxford, Ohio, U.S.A. He has worked in agency, in-house, corporate, non-profit and freelance environments with and for organizations including Dennard, Lacey and Associates of Dallas, Southwest Airlines, HKS Architects, Water is Basic and the Dallas-based public broadcasting television station, KERA. His work has earned regional and national awards, and has been published nationally; he has presented his research internationally. Dennis has a BA in English with a focus in Creative Writing, and a BFA in Design Communication from Texas Tech University. He also holds an MFA in Applied Design Research from the University of North Texas. 